\title{
Environmental impact caused by fungal and particle contamination of Portuguese swine
}

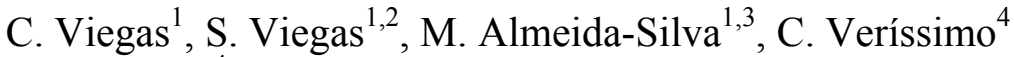 \\ \& R. Sabino ${ }^{4}$ \\ ${ }^{I}$ Escola Superior de Tecnologia da Saúde de Lisboa, \\ Instituto Politécnico de Lisboa, Portugal \\ ${ }^{2}$ CIESP - Centro de Investigação e Estudos em Saúde Pública, \\ Escola Nacional de Saúde Pública, ENSP, \\ Universidade Nova de Lisboa, Portugal \\ ${ }^{3} U R S N$, IST/ITN, Instituto Superior Técnico, \\ Universidade Técnica de Lisboa, Sacavém, Portugal \\ ${ }^{4}$ Laboratório de Micologia, \\ Instituto Nacional de Saúde Dr. Ricardo Jorge, Lisboa, Portugal
}

\begin{abstract}
Social concerns for environmental impact on air, water and soil pollution have grown along with the accelerated growth of pig production. This study intends to characterize air contamination caused by fungi and particles in swine production, and, additionally, to conclude about their eventual environmental impact. Fiftysix air samples of 50 litters were collected through impaction method. Air sampling and particle matter concentration were performed in indoor and also outdoor premises. Simultaneously, temperature and relative humidity were monitored according to the International Standard ISO 7726 - 1998. Aspergillus versicolor presents the highest indoor spore counts $\left(>2000 \mathrm{CFU} / \mathrm{m}^{3}\right)$ and the highest overall prevalence $(40.5 \%)$, followed by Scopulariopsis brevicaulis $(17.0 \%)$ and Penicillium sp. (14.1\%). All the swine farms showed indoor fungal species different from the ones identified outdoors and the most frequent genera were also different from the ones indoors. The distribution of particle size showed the same tendency in all swine farms (higher concentration values in $\mathrm{PM}_{5}$ and $\mathrm{PM}_{10}$ sizes). Through the ratio between the indoor and outdoor values, it was possible to conclude that $\mathrm{CFU} / \mathrm{m}^{3}$ and particles presented an eventual impact in outdoor measurements. Besides its potential environmental impact,
\end{abstract}


there is also a public health and occupational threat due to the presence and concentration of the fungal species identified in swine's air.

Keywords: swine, fungal contamination, particles, air contamination, environmental impact.

\section{Introduction}

In recent decades, farmers in Europe and North America have enlarged livestock production techniques by using more enclosed and densely stocked housing (confinement buildings). The design of these buildings leads to high animal concentrations, and their wastes and feed as well. This results in high levels of dusts, gases, microbes, microbial metabolites, and other potential health hazards in the air [1].

Social concerns for environmental impact on air, water and soil pollution grew along with the accelerated growth of the industry. Needless to say, a massive amount of waste water and aerial contaminants emitted from pig production can cause serious environmental problems, which prompted the establishment of strict environmental regulations related to pig production $[2,3]$.

The air surrounding swine confinement production facilities contains odors, gases, and airborne particles carried from the buildings by ventilated air [4]. Dust particles adsorb volatile organic compounds and pathogenic organisms, acting as their airborne carrier $[5,6]$. Dust particles with a diameter between 0.5 and $10 \mu \mathrm{g}$ are generally classified as respirable aerosol particles, which can penetrate into lower respiratory system of humans and cause respiratory diseases, such as bronchitis, asthma, and pneumonia [7, 8]. Exposure to organic dust in concentrations greater than $2.5 \mathrm{mg} / \mathrm{m}^{3}$ from the pig-confinement building has been associated with symptoms of respiratory disease [1].

The airborne dust found in swine confinement buildings contains, among other microorganisms, large numbers of mesophillicmolds [9], and they can be disseminated outside swine buildings through dust particles. Its well-recognized that exposure to certain fungi can cause human illness. Fungi cause adverse human health effects through three specific mechanisms: generation of a harmful immune response (e.g., allergy or hypersensitivity pneumonitis), direct infection by the fungal organism and also by toxic-irritant effects from mold byproducts, such as mycotoxins [10].

This study intends to characterize air contamination caused by fungi and particles in swine production, and additionally, to conclude about their eventual environmental impact.

\section{Materials and methods}

A descriptive study was developed in order to assess air contamination caused by fungi and particles contamination in seven Portuguese swine farms. This assessment was carried out in the winter, when ventilation rates were low, in order to assess contamination during a critical scenario. 
Fifty six air samples of 50 litters were collected through impaction method. Air sampling and particle matter concentration measurement (5 different sizes, namely $\mathrm{PM}_{0.5} ; \mathrm{PM}_{1} ; \mathrm{PM}_{2.5} ; \mathrm{PM}_{5} ; \mathrm{PM}_{10}$ ) were performed indoor and also outside premises to conclude about an eventual environmental impact. Simultaneously, temperature and relative humidity were monitored through the equipment Babouc, LSI Sistems and according to the International Standard ISO 7726 1998.

Air samples were collected at one meter height with a flow rate of $140 \mathrm{~L} /$ minute, onto malt extract agar (MEA) supplemented with the antibiotic chloramphenicol $(0.05 \%)$. After laboratory processing and incubation of the collected samples, quantitative (colony forming units $-\mathrm{CFU} / \mathrm{m}^{3}$ ) and qualitative results were obtained, with identification of the isolated fungal species. Whenever possible, filamentous fungi were identified to the species level, since adverse health effects vary according to fungal species within the same genera $[11,12]$. Identification of filamentous fungi was carried out by macroscopic and microscopic observations, using lactophenol blue stain and achieved through comparison of morphological characteristics listed in illustrated literature [12].

\section{Results and discussion}

\subsection{Fungal contamination}

In the seven swine studied, Aspergillus versicolor presents the highest indoor spore counts $\left(>2000 \mathrm{CFU} / \mathrm{m}^{3}\right)$ and the highest overall prevalence $(40.5 \%)$, followed by Scopulariopsis brevicaulis (17.0\%) and Penicillium sp. (14.1\%).

All the swine farms showed indoor fungal species different from the ones identified outdoors. Moreover, the most frequent genera were also different from the ones indoors (Table 1).

Table 1: $\quad$ Most frequent fungi identified indoor and outdoor air.

\begin{tabular}{lclc}
\hline \hline \multicolumn{1}{c}{ Indoor } & Frequency (\%) & \multicolumn{1}{c}{ Outdoor } & Frequency (\%) \\
\hline \hline Aspergillus versicolor & 40.5 & Cladosporium sp. & 17.9 \\
Scopulariopsis brevicaulis & 17.0 & Scytalidium $\mathrm{sp}$. & 15.8 \\
Penicillium sp. & 14.1 & Penicillium sp. & 15.8 \\
Others & 28.4 & Chrysosporium sp. & 10.5 \\
& & Others & 40.0 \\
\hline
\end{tabular}

The exposure of workers from swine confinement buildings to respiratory hazards has been reported elsewhere in Europe [13-15], Asia [16, 17] and America [7, 18]. To our notice, analogous data has not been reported for Portugal and this omission has hindered the development of policies in the area of occupational health and farm safety. Generally, dust is recognized to adsorb and transport odorous compounds [19] and biological agents [20,21]. Especially, biological factors associated with airborne dust are the most important hazards in pig buildings and include allergenic and/or toxic agents as well as infectious agents such as bacterial endotoxin, fungal mycotoxin and microbial cell components [16]. 
Regarding the most common fungi found in air, Aspergillus versicolor disseminates easier in the air than other Aspergillus species, such as A. fumigatus. This may be due to the need of less water content [22], which is the eventual cause to present the highest indoor spore counts. Aspergillus versicolor is known as being the major producer of the hepatotoxic and carcinogenic mycotoxin sterigmatocystin. The toxicity of this mycotoxin is manifested primarily in liver and kidney [23]. Due to their easier detection, fungi are often used as an indirect indicator of mycotoxins presence both in agricultural and occupational settings. Therefore, we must consider the eventual exposure not only to fungal particles, but also to the hepatotoxic and carcinogenic mycotoxin sterigmatocystin [24]. This mycotoxin is closely related to aflatoxin mycotoxins as a precursor of aflatoxin biosynthesis [25] and is classified as an International Agency for Research on Cancer class 2B carcinogen (i.e., as possibly carcinogenic to humans) [26]. Aspergillus versicolor was also the most frequently found in surfaces from the studied swine [27] corroborating the dissemination potential of Aspergillus genera [28, 29], and in particularly from this species [22]. Also in another study [30], Aspergillus sp. and Penicillium sp. (the third most frequently found) were the most frequent in swine air.

Exposure to Scopulariopsis brevicaullis, the second most frequently species isolated from the air, has been associated with cases of occupational allergy. Scopulariopsis brevicaulis is a well-known agent of onychomycosis being, in this case, the surfaces' contamination the potential risk for workers' health $[31,32]$.

Since there are no published thresholds values regarding to fungal contamination is essential to perform a comparison between fungal levels indoors and outdoors. Despite outdoor air is a major source of the fungi found indoors, in the studied swine there was no coincidence between fungal species in indoor and outdoor air (Table 1) and all the analyzed swine had two or more indoor spaces with a fungal load higher than outdoor (Table 2), suggesting in both situations that fungal contamination came from within [33].

Table 2: Quantification of air fungal load in indoor and outdoor of the seven swine studied.

\begin{tabular}{ccc}
\hline \hline Swine farm & Indoor* CFU/m $^{\mathbf{3}}$ & Outdoor $\mathbf{C F U} / \mathbf{m}^{\mathbf{3}}$ \\
\hline \hline $\mathrm{A}$ & 185 & 240 \\
\hline $\mathrm{B}$ & 529 & 560 \\
\hline $\mathrm{C}$ & 364 & 200 \\
\hline $\mathrm{D}$ & 1010 & 220 \\
\hline $\mathrm{E}$ & 413 & 340 \\
\hline $\mathrm{F}$ & 614 & 140 \\
\hline $\mathrm{G}$ & 153 & 140 \\
\hline
\end{tabular}

*Mean values.

\subsection{Particle contamination}

The distribution of particles' size showed the same tendency in all swine farms, higher concentration of particles with $\mathrm{PM}_{5}$ and $\mathrm{PM}_{10}$ sizes (Table 3). 
The majority of the previous studies estimated particles' exposure by dust concentration measurements and were often carried out by means of gravimetric systems, giving only information of the total mass concentration obtained and separating the data in "total dust" and "respirable dust". Very few studies on agricultural farms investigated the particles' exposure regarding their size. The size, however, affects particles' deposition in the respiratory system, resulting in different health effects [34]. Our study gives information concerning five different particles' sizes and this data allows the achievement of more detailed information concerning contamination with particles and their possible health effects.

Data obtained showed higher particle concentration with $\mathrm{PM}_{5}$ size and, predominantly $\mathrm{PM}_{10}$ (Table 3 ), indicating that swine dust can penetrate into the gas exchange region of the lung $\left(\mathrm{PM}_{5}\right)$ and may also produce disease by impacting in the upper and larger airways below the vocal cords $\left(\mathrm{PM}_{10}\right)$ [35].

Table 3: Average values of particulate matter in 5 different sizes $\left(\mathrm{PM}_{0.5}\right.$, $\mathrm{PM}_{1}, \mathrm{PM}_{2.5}, \mathrm{PM}_{5}$ and $\mathrm{PM}_{10}$ ) per swine (values in $\mathrm{mg} / \mathrm{m}^{3}$ ).

\begin{tabular}{c|c|c|c|c|c}
\hline \hline $\mathrm{ID}$ & $\mathrm{PM}_{0.5}$ & $\mathrm{PM}_{1}$ & $\mathrm{PM}_{2.5}$ & $\mathrm{PM}_{5}$ & $\mathrm{PM}_{10}$ \\
\hline $\mathrm{A}$ & 0.008 & 0.013 & 0.046 & 0.439 & 2.212 \\
\hline $\mathrm{B}$ & 0.020 & 0.044 & 0.186 & 1.270 & 5.289 \\
\hline $\mathrm{C}$ & 0.003 & 0.009 & 0.079 & 0.968 & 5.091 \\
\hline $\mathrm{D}$ & 0.003 & 0.008 & 0.046 & 0.459 & 2.039 \\
\hline $\mathrm{E}$ & 0.023 & 0.043 & 0.116 & 0.604 & 1.913 \\
\hline $\mathrm{F}$ & 0.001 & 0.008 & 0.067 & 0.684 & 3.122 \\
\hline $\mathrm{G}$ & 0.004 & 0.007 & 0.037 & 0.435 & 2.250 \\
\hline
\end{tabular}

Numerous articles have been published regarding the adverse respiratory health consequences of working in intensive livestock houses. Threshold exposure limit guidelines are not always applied in the intensive animal industry, but they are essential for protection workers health [36].

A consistent relationship between environmental exposure in livestock buildings and deficient lung function changes and/or respiratory symptoms in workers has been observed in four separate studies [1, 37-39]. These studies identified exposure-response thresholds for workers, on the basis of which thresholds for poultry and swine confinement buildings were suggested. Previous dose-response studies with swine workers [40] have resulted in exposure limit recommendations of $2.4 \mathrm{mg} / \mathrm{m}^{3}$ of total dust and $0.23 \mathrm{mg} / \mathrm{m}^{3}$ of respirable dust [36]. Our results showed values higher than these exposure limits recommendation, in some cases (Swine B and C), two-fold higher (Table 3). Moreover, concentrations higher than $2.5 \mathrm{mg} / \mathrm{m}^{3}$ have been associated with symptoms of respiratory disease [1].

In a more detailed examination of the same data, it is possible to observe that Farms B and C presented higher levels of contamination, particularly in $\mathrm{PM}_{5}$ and $\mathrm{PM}_{10}$ (Figure 1). These two farms were the ones having only natural ventilation as a ventilation resource. The others swine farms have a combination between natural and mechanical (exhaust) ventilation. The same trend in the results was 


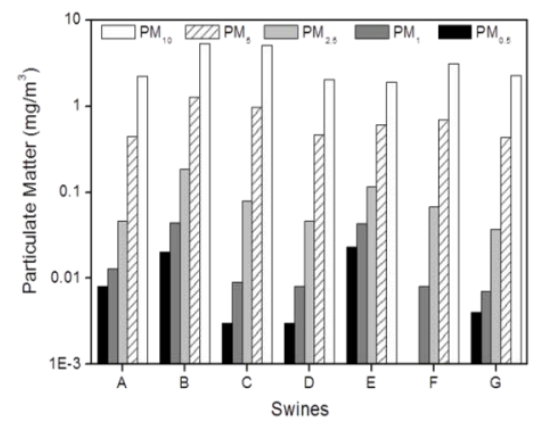

Figure 1: $\quad$ Particle distribution in swine farms.

obtained by Kim and colleagues where the concentrations and emissions of dust were highest in the naturally ventilated pig buildings [16].

There is little need of manual work in current systems of pig production because most of the confinement pig houses are constructed automatically. In Portugal, however, there are some activities that still need farmer's intervention, such as cutting piglets' tails and vaccination. Because of that, there is an increase of the expended time in those places, and consequently an increase of the exposure to particles and fungi [27].

There is no agreement in the literature about which is the swine phases with higher concentration of particles. Our results are consistent with other authors who suggest that dust concentrations are higher in fattening rooms than in nurseries, considering the $\mathrm{PM}_{10}$ [41] (Figure 2b).

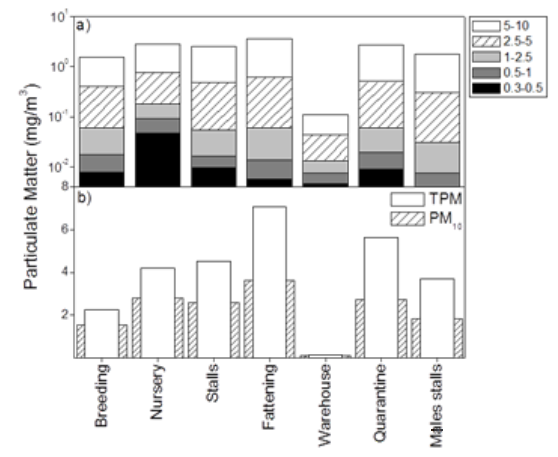

Figure 2: a) Particles distribution in swine different places by granulometries;

b) $\mathrm{PM}_{10}$ distribution in swine different places and total particulate matter (TPM="total dust").

Comparing our results for TPM with limit recommendation defined by other authors [40] it is possible to observe in Figure $2 b$ that in all assessed places this value was exceeded, with the exception of breeding and warehouse. 
According to Nonnenmann and colleagues [42], there is a strong linear relationship between the total weight of the pigs in the room and the dust concentration. In that study, dust concentration more than doubled as the pigs grew. Therefore, the amount of animal mass will be a major factor influencing the dust concentration [36].

However, as we can observe in Figure 2a), nursery presents the highest concentration of minor particles $(0.3 \mu \mathrm{g}-0.5 \mu \mathrm{g})$. In these places pigs are on a special status condition, with mobility difficulties, which hampers the maintenance of the cells and, consequently, leads to the accumulation of fecal material. This evidence suggests that the smallest particles contain a large amount of fecal matter [43].

\subsection{Environmental variables influence}

Regarding particles role as fungal load carrier, $\mathrm{PM}_{2.5}$ and $\mathrm{PM}_{5}$ contributed with $38.0 \%$ and $31.0 \%$, respectively, to explanation of $\mathrm{CFU} / \mathrm{m}^{3}$ variation, being the highest contribution from particles in fungal dissemination by air (Figure 3). In fact, fungal spore sizes range typically from 2 to $10 \mu \mathrm{m}$ among species and vary even among spores from the same species [44].

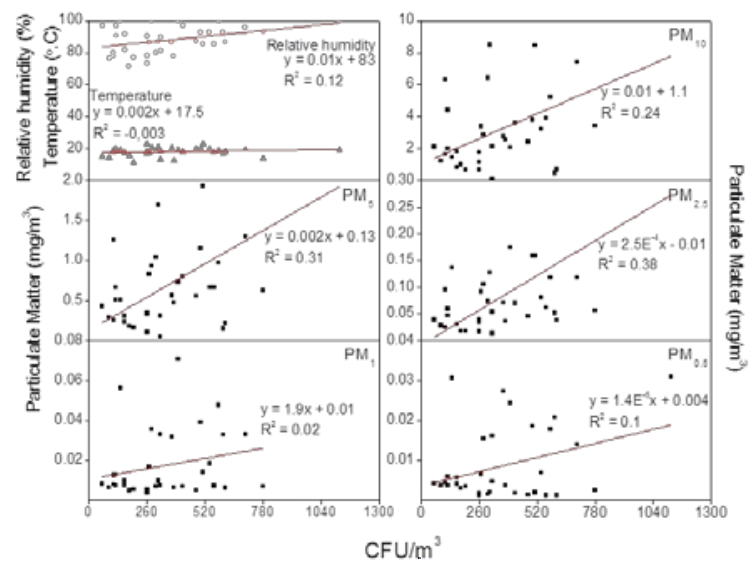

Figure 3: Relation between relative humidity, temperature, $\mathrm{PM}_{10}, \mathrm{PM}_{5}$, $\mathrm{PM}_{2.5}, \mathrm{PM}_{1}, \mathrm{PM}_{0.5}$ with $\mathrm{CFU} / \mathrm{m}^{3}$.

In a study developed by Halstensen and colleagues in a grain farming setting, dust levels were the most important predictive factor for microbial exposure preventive practices. Despite only data regarding "total dust" was presented, was possible to conclude that any dustiness prevention or protection will decrease microbial exposure [45]. Same relation was corroborated only when particles with $\mathrm{PM}_{2.5}$ and $\mathrm{PM}_{5}$ size were analysed (Figure 4).

This is probably due to other environmental conditions from which fungal concentration depends, besides dustiness [46]. 


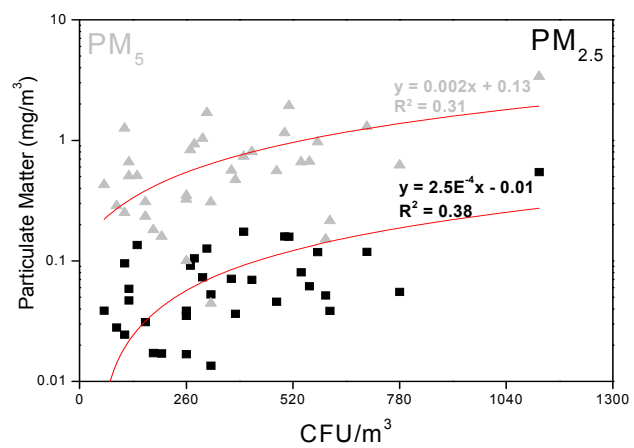

Figure 4: $\quad \mathrm{PM}_{2.5}$ and $\mathrm{PM}_{5}$ contribution to $\mathrm{CFU} / \mathrm{m}^{3}$ variation explanation.

Relative humidity contributed only in $37.0 \%$ to the explanation of variation of particles sized as PM1, being this the highest contribution from humidity parameter to the different distribution of particles size (Figure 5).

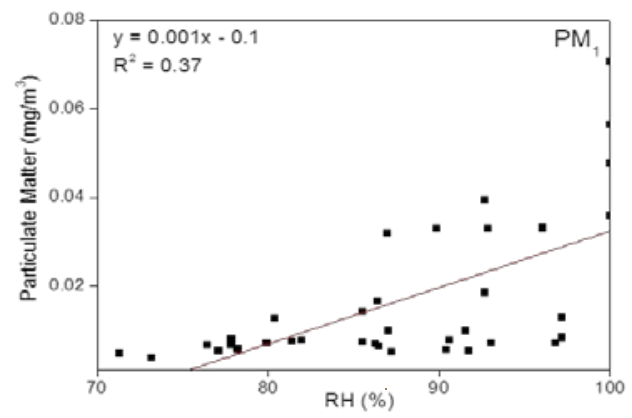

Figure 5: Relative humidity contribution in $\mathrm{PM}_{1}$ variation.

Dust concentration may be influenced by different factors, including the relative humidity [47]. In 2007, a literature review developed by Wolkoff and Kjærgaard established that relative humidity has effect on the formation and size of secondary aerosols and therefore on their deposition [48]. Low relative humidity appears to enhance particle deposition of fine particles $(<1 \mu \mathrm{m})$ [49] and high relative humidity likewise $[50,51,48]$. On the other hand, resuspension of particles $(>1 \mu \mathrm{m})$ increases with size [52], and with the increase of relative humidity up to about $75 \% \mathrm{RH}$ [48]. Considering that in our study relative humidity results were all above $70 \%$, the positive contribution obtained to $\mathrm{PM}_{1}$ variation can be due also to re-suspension.

\subsection{Ratio indoor/outdoor}

Regarding the fungal load found indoor and outdoor, different fungal counts were obtained in our study $\left(120 \mathrm{CFU} / \mathrm{m}^{3}-4100 \mathrm{CFU} / \mathrm{m}^{3}\right)$ and in a study 
performed by Duchaine et al. $\left(547 \mathrm{CFU} / \mathrm{m}^{3}-2862 \mathrm{CFU} / \mathrm{m}^{3}\right)$. This may be due to different procedures of building maintenance [53], and also differences in other variables that are known to influence swine fungal contamination, such as moldy livestock feeding materials, moldy hay, animal bedding, and feces [54].

Through the ratio between indoor and outdoor values, it was possible to conclude that $\mathrm{CFU} / \mathrm{m}^{3}$ and particles presented an impact in outdoor measurements (Table 4).

Table 4: $\quad$ Ratio between values of the measured parameters obtained from indoors (I) and outdoors (O).

\begin{tabular}{cc}
\hline \hline Parameters & Ratio (I/O) \\
\hline \hline Temperature & 1.1 \\
\hline Relative humidity & 0.8 \\
\hline $\mathrm{CFU} / \mathrm{m}^{3}$ & 1.9 \\
\hline $\mathrm{PM}_{0.5}$ & 1.2 \\
\hline $\mathrm{PM}_{1.0}$ & 1.4 \\
\hline $\mathrm{PM}_{2.5}$ & 3.0 \\
\hline $\mathrm{PM}_{5.0}$ & 9.8 \\
\hline $\mathrm{PM}_{10}$ & 23.7 \\
\hline
\end{tabular}

According to Table 4, it is possible to observe a positive relation between the increment of particle diameter and that ratio. This fact may provide negative impacts to the surroundings atmospheric air because of the particles exposure, and also due to gases and odorants that may be fixed onto dust [41].

The level of dairy limit values for $\mathrm{PM}_{10}$ in Europe is $50 \mu \mathrm{g} / \mathrm{m}^{3}$ [55]. Although the collected samples in this study were not carried out for $24 \mathrm{~h}$ it is important to refer that in all studied swine the $\mathrm{PM}_{10}$ assessed outdoor exceeded those limit value.

Data obtained through ratio between fungal contamination indoor and outdoor corroborate the negative environmental impact caused by fungal contamination from this industry, and that was also described by Donham and Thu [4]. However, research on dimension of this impact in the surroundings of swine farms is still needed.

\section{Conclusions}

Beyond the potential environmental impact, public health and occupational threat due to the presence of the most often identified fungal species in swine air has to be considered. More research on dimension of this impact in the surroundings of swine farms is still needed. Obtained results also demonstrate high levels of contamination by particulate matter in the swine farms studied, particularly $\mathrm{PM}_{5}$ and $\mathrm{PM}_{10}$ sizes. 


\section{Acknowledgements}

This work was supported by the Portuguese Authority for Work Conditions. We also gratefully acknowledge Fundaçãopara a Ciência e Tecnologia (FCT) for funding M. Almeida-Silva by PhD fellowship (SFRH/BD/69700/2010).

\section{References}

[1] Donham K, Haglind P, Petersen Y, Rylander R and Belin L: Environmental and health studies of farm workers in Swedish confinement buildings. British J Ind Med. 46: pp. 31-37, 1989.

[2] Gay S, Schmidt D, Clanton C, Janni K, Jacobson L and Weisberg S: Odor, total reduced sulfur, and ammonia emissions from animal housing facilities and manure storage units in Minnesota. Appl Eng Agric. 19: pp. 347-360, 2003.

[3] Wathes $\mathrm{C}$, Jones $\mathrm{C}$ and Webster A: Ventilation, air hygiene and animal health. Vet Rec 10: pp. 554-559, 1998.

[4] Donham K and Thu K: Understanding the impacts of large-scale swine production. Proceedings from an Interdisciplinary Scientific Workshop. Iowa, 1995.

[5] Donaldson A: Factors influencing the dispersal, survival and deposition of airborne pathogens of farm animals. Vet Bull. 48: pp. 83-94, 1978.

[6] Bottcher R: An environmental nuisance: odor concentrated and transported by dust Chem Sense. 26: pp. 327-331, 2001.

[7] Cormior Y, Tremblay G, Meriaux A, Brochu G and Lavoie J: Airborne Microbial Content in Two Types of Swine Confinement Buildings in Quebec. Am Ind Hyg Assoc. 51(6): pp. 304-309, 1990.

[8] Olson D and Bark S: Health hazards affecting the animal confinement farm worker. Am Assoc Occup Health Nurse J. 44: pp. 198-204, 1996.

[9] Donham K, Scallon L, Popendorf W, Treuhaft M and Roberts R: Characterization of dust collected from swine confinement buildings. Am. Ind. Hyg. Assoc. J. 47: pp. 404-410, 1986.

[10] Bush R, Portnoy J, Saxon A, Terr A and Wood R: The medical effects of mold exposure J Allergy Clin Immunol. 17:2: pp. 326-333, 2006.

[11] Rao C, Burge $\mathrm{H}$ and Chang J: Review of quantitative standards and guidelines for fungi in indoor air. J Air Waste Manage Assoc., 46: pp. 899908, 1996.

[12] Hoog C, Guarro J, Gené G and Figueiras M: (2th ed). Atlas of Clinical Fungi. Centraalbureau voor Schimmelcultures, 2000.

[13] Portengen L, Preller L, Tielen M, Doekes G and Heederik D: Endotoxin exposure and atopic sensitization in adult pig farmers. $J$ Allergy Clin Immunol. 115, pp: 797-802, 2005.

[14] Radon K, Danuser B, Iversen M, Monso E, Weber C, Hartung J, Donham K, Palmgren U and Nowak D: Air Contaminants in Different European Farming Environments. Ann Agric Environ Med. 9: pp. 41-48, 2002. 
[15] Simpson J, Niven R, Pickering A, Oldham A, Fletcher A and Francis H: Comparative Personal Exposures to Organic Dusts and Endotoxin. Ann Occup Hyg Vol. 43: pp. 107-115, 1999.

[16] Kim K, Ko H, Kim Y and Kim C: Assessment of Korean farmer's exposure level to dust in pig buildings. Ann Agric Environ Med. 15: pp. 51-58, 2008.

[17] Chang C, Chung H, Huang $\mathrm{C}$ and $\mathrm{Su} \mathrm{H}$ : Exposure of Workers to Airborne Microorganisms in Open-Air Swine Houses. Appl Environ Microbiol. 67(1): pp. 155-161, 2001.

[18] Donham K: The concentration of swine production: effects on swine health, productivity, human health, and the environment. Toxicology. 16(3): pp. 559-597, 2000.

[19] Carpenter G: Dust in livestock buildings - review of some aspects. J Agric Eng Res, 33: pp. 227-241, 1986.

[20] Kim K, Ko H, Lee K, Park J and Kim C: Temporal and spatial distributions of aerial contaminants in an enclosed pig building in winter. Environ Res, 99: pp. 150-157, 2005.

[21] Robertson $\mathrm{J}$ and Frieben $\mathrm{W}$ : Microbial validation of ventilation filters. Biotechnol Bioeng, 26: pp. 828-835, 1984.

[22] Duchaine $C$ and Mériaux A: The importance of combining air sampling and surface analysis when studying problematic houses for mold biodiversity determination. Aerobiologia, 17, 2: pp. 121-125, 2001.

[23] Engelhart S, Loock A, Skutlarek D, Sagunski H, Lommel A, Harald F and Exner M: Occurrence of Toxigenic Aspergillus versicolor Isolates and Sterigmatocystin in Carpet Dust from Damp Indoor Environments. Applied and Environmental Microbiology, 68 (8): pp. 3886-3890, 2002.

[24] Thrane U, Adler A, Clasen P, Galvano F, Langseth W, Lew H, Logrieco A, Nielsen $\mathrm{K}$ and Ritieni A: Diversity in metabolite production by Fusarium langsethiae, Fusarium poae, and Fusarium sporotrichioides. Int. J. Food Microbiol, 95: pp. 257-266, 2004.

[25] Barnes S, Dola T, Bennett J and Bhatnagar D: Synthesis of sterigmatocystin on a chemically defined medium by species of Aspergillus and Chaetomium. Mycopathologia, 125: pp. 173-178, 1994.

[26] International Agency for Research on Cancer. Some naturally occurring substances. Monographs, vol. 10, Suppl. 7, p. 72. International Agency for Research on Cancer, Lyon, France. 1987.

[27] Viegas C, Carolino E, Sabino R, Viegas S and Veríssimo C: Fungal contamination in swine: An occupational health treat. Journal of Toxicology and Environmental Health, Part A. 2013. Accepted for publication.

[28] Bex V, Mouilleseaux A and Causse R: A survey of Aspergillus contamination in a hospital during renovation. Healthy Buildings. 1: pp. 359-364, 2000.

[29] Van Den Bergh M, Verweij P and Voss A: Epidemiology of nosocomial fungal infections: invasive aspergillosis and the environment. Diagnostic Microbiology and Infectious Disease. 34: 3: pp. 221-227, 1999. 
[30] Jo W and Kang J: Exposure levels of airborne bacteria and fungi in Korean swine and poultry sheds. Archives of Occupational \& Environmental Health. 60: 3: pp. 140-146, 2005.

[31] Tosti A, Piraccini B, Stinchi M and Lorenzi S: Onychomycosis due to Scopulariopsis brevicaulis: clinical features and response to systemic antifungals. Br J Dermatol. 135(5): pp. 799-802, 1996.

[32] Ponikau J, Sherris D, Kern E, Homburger H, Frigas E, Gaffey T and Roberts G: The diagnosis and incidence of allergic fungal sinusitis. Mayo Clin Proc. 74(9): pp. 877-84, 1999.

[33] Kemp P, Neumeister-Kemp H, Esposito B, Lysek G and Murray F: Changes in airborne fungi from the outdoors to indoor air; Large HVAC systems in nonproblem buildings in two different climates. American Industrial Hygiene Association 64: pp. 269-275, 2003.

[34] Lee S, Adhikari A, Grinshpun S, McKay R, Shukla R and Reponen T: Personal Expo-sure to Airborne Dust and Microorganisms in Agricultural Environments. Journal of Occupational and Environmental Hygiene, 3: pp. 118-130, 2006.

[35] Vincent $\mathrm{J}$ and Mark D: The basis of dust sampling in occupational hygiene: a critical review. Annals of Occupational Hygiene, 24: pp. 375-390, 1981.

[36] Pedersen S, Nonnenmann M, Rautiainen R, Demmers T, Banhazi T and Lyngbye M. Dust in Pig Buildings. Journal of Agricultural Safety and Health 6(4): pp. 261-274, 2000.

[37] Reynolds, S., K. Donham, P. Written, J. Merchant, L. Burmeister and W. Poppendorf. 1996. Longitudinal evaluation of dose-response relationships for environmental exposures and pulmonary function in swine production workers. Am J Ind Med. 29: pp. 33-40, 1996.

[38] Donham K: A historical overview of research on the hazards of dust in livestock buildings. In Dust Control in Animal Production Facilities, Proc. Congress in Aarhus, Denmark, 30 May-2 June: pp. 13-21, 1999. Horsens, Denmark: Danish Institute of Agricultural Sciences, Research Centre Bygholm.

[39] Donham K, Reynolds S, Whitten P, Merchant J, Burmeister L and Poppendorf W: Respiratory dysfunction in swine production facility workers: Dose-response relationships of environmental exposures and pulmonary function. Am J Ind Med 27: pp. 405-418, 1995.

[40] Donham K and Cumro D: Setting maximum dust exposure levels for people and animals in livestock facilities. In Dust Control in Animal Production Facilities, Proc. Congress in Aarhus, Denmark, 30 May-2 June, pp. 93-110, 1999. Horsens, Denmark: Danish Institute of Agricultural Sciences, Research Centre Bygholm.

[41] Hamon L, Andrès Y and Dumont E: Aerial Pollutants in Swine Buildings: A Review of Their Characterization and Methods to Reduce Them. Environ. Sci. Technol. 46: pp. 12287-12301, 2012.

[42] Nonnenmann M, Rautiainen K, Donham S, Kirychuk S and Donham K: Relationships of air quality and productivity in intensive swine housing. Agriculture Pra.10: pp. 15, 1989. 
[43] Pickrell J, Heber A, Murphy J, Henry S, May M, Nolan D, Oehme F, Gillespie J and Schoneweis D: Characterization of particles, ammonia and endotoxin in swine confinement operations. Vet. Hum. Toxicol. 35(5): pp. 421-428, 1993.

[44] Reponen T, Willeke K, Ulevicius V, Reponen A, Grinshpun S: Effects of relative humidity on the aerodynamic diameter and respiratory deposition of fungal spores. Atmos Environ 30: pp. 3967-3974, 1996.

[45] Halstensen A, Nordby K, Wouters I and Eduard W: Determinants of Microbial Exposure in Grain Farming. Ann. Occup. Hyg., 51, 7: pp. 581592, 2007.

[46] Kasprzyk I: Aeromycology - main research fields of interest during the last 25 years. Ann Agric Environ Med, 15: pp. 1-7, 2008.

[47] Honey L and McQuitty J: Some physical factors affecting dust concentration in a pig facility. Canadian Agricultural Engineering. 21 (1): pp. 9-14, 1978.

[48] Wolkoff P and Kjærgaard S: The dichotomy of relative humidity on indoor air quality. Environment International 33: pp. 850-857, 2007.

[49] Litvak A, Gadgil A and Fisk W: Hygroscopic fine mode particle deposition on electronic circuits and resulting degradation of circuit performance: an experimental study. Indoor Air, 10: pp. 47-56, 2000.

[50] Miguel A, Reis A and Aydin M: Aerosol particle deposition and distribution in bifurcating ventilation ducts. J Hazard Mater 116: pp. 249-55, 2004.

[51] Fromme H, Twardella D, Dietrich S, Heitmann D, Schierl R, Liebl B, et al. Particulate matter in the indoor air of classrooms-exploratory results from Munich and surrounding area. Atmos Environ. 41: pp. 854-66, 2007.

[52] Blondeau P, Iordache V, Poupard O, Gemin D and Allard F: Relationship between outdoor and indoor air quality in eight French schools. Indoor Air. 15: pp. 2-12, 2005.

[53] Duchaine C, Grimard Y and Cormier Y: Influence of Building Maintenance, Environmental Factors, and Seasons on Airborne Contaminants of Swine Confinement Buildings, AIHAJ - American Industrial Hygiene Association, 61: 1: pp. 56-63, 2000.

[54] Adhikari A, Sen M, Gupta-Bhattacharya S and Chanda S: Volumetric assessment of airborne fungi in two sections of a rural indoor dairy cattle shed. Environ Im. 29: pp. 1071-1078, 2004.

[55] Council Directive 1999/30/CE, $22^{\text {nd }}$ April 1999, relating to limit values for sulphur dioxide, nitrogen dioxide and oxides of nitrogen, particulate matter and lead in ambient air. 